\title{
Nephrogenic Systemic Fibrosis Risk Assessment and Skin Biopsy Quantification in Patients with Renal Disease following Gadobenate Contrast Administration
}

\author{
(D)E. Kanal, (D).J. Patton, (DI. Krefting, and (D). Wang
}

\begin{abstract}
BACKGROUND AND PURPOSE: Nephrogenic systemic fibrosis following administration of intravenous gadobenate during MR imaging is rare. This study aimed to analyze any nephrogenic systemic fibrosis-related risks and quantify skin gadolinium levels in patients with impaired renal function but without nephrogenic systemic fibrosis who had received gadobenate.
\end{abstract}

MATERIALS AND METHODS: In this retrospective study with a prospective skin biopsy phase, patients with estimated glomerular filtration rates of $<60 \mathrm{~mL} / \mathrm{min} / 1.73 \mathrm{~m}^{2}$ undergoing contrast-enhanced MR imaging from July 2007 through June 2014 were screened for nephrogenic systemic fibrosis using a questionnaire. This was highly sensitive but not specific and reliably excluded nephrogenic systemic fibrosis if responses to at least 6 of the 8 questions were negative. If no nephrogenic systemic fibrosis was detected, a skin biopsy was requested.

RESULTS: Of 2914 patients who met these criteria, 1988 were excluded for various reasons. Of the remaining 926 patients, 860 were screened negative for nephrogenic systemic fibrosis. Of these, $17(2 \%)$ had estimated glomerular filtration rates of $<15 \mathrm{~mL} /$ $\mathrm{min} / 1.73 \mathrm{~m}^{2}, 51(6 \%)$ had levels of $15<30 \mathrm{~mL} / \mathrm{min} / 1.73 \mathrm{~m}^{2}, 234(27 \%)$ had levels of $30<45 \mathrm{~mL} / \mathrm{min} / 1.73 \mathrm{~m}^{2}$, and 534 (62\%) had levels of $45<60 \mathrm{~mL} / \mathrm{min} / 1.73 \mathrm{~m}^{2}$. Of the 66 who were not cleared of nephrogenic systemic fibrosis by the questionnaire, 6 patients were evaluated by a dermatologist and confirmed not to have nephrogenic systemic fibrosis (no biopsy required).

CONCLUSIONS: A diagnosis of nephrogenic systemic fibrosis was excluded in 860 patients with impaired renal function who were followed up and received gadobenate during MR imaging. In 14 such patients who underwent at least 1 gadobenate-enhanced MR imaging examination and did not have nephrogenic systemic fibrosis, gadolinium levels in the skin were exceedingly low.

ABBREVIATIONS: eGFR = estimated glomerular filtration rate; GBCA = gadolinium-based contrast agents; ICP-MS = inductively coupled plasma mass spectrometry; NSF = nephrogenic systemic fibrosis

W hile the relative nephrogenic systemic fibrosis (NSF)related safety of at least some of the macrocyclic agents has been established, there do not seem to be any confirmed cases of NSF following the prior unconfounded administration of the linear gadolinium-based contrast agent gadobenate. ${ }^{1}$ Since gadolinium-based contrast agents (GBCA) received regulatory approval in 1988, >450 million doses have been administered

Received October 24, 2019; accepted after revision December 18. Departments of Radiology (E.K.) and Dermatology (T.J.P.), University of Pittsburgh Medical Center and University of Pittsburgh, Pittsburgh, Pennsylvania; Division of Medical Imaging and Radiation Medicine (I.K.); and Office of Pharmacovigilance and Epidemiology (C.W.), US Food and Drug Administration, Silver Spring, Maryland. Dr Wang is currently with Ascentage Pharma Group, Rockville, Maryland.

This work was funded, in part, by FDA Cooperative Agreement U01 FD004713.

Please address correspondence to Ira Krefting, MD, US Food and Drug Administration, 10903 New Hampshire Ave, Building 22, Room 5402, Silver Spring, MD 20993; e-mail: Ira.Krefting@fda.hhs.gov

- Indicates open access to non-subscribers at www.ajnr.org

http://dx.doi.org/10.3174/ajnr.A6448 worldwide. ${ }^{1}$ While GBCA have a favorable pharmacologic safety profile, evidence of long-term retention in human tissues and occurrence of NSF in some patients with severely compromised renal function have raised concerns. ${ }^{2,3}$

The connection between gadolinium exposure and NSF was recognized by Grobner, ${ }^{4}$ in 2006. Gadolinium levels are elevated in the biopsies of skin lesions in patients with NSF. ${ }^{3,5-8}$ In 2014, Kanda et $\mathrm{al}^{9}$ noted retention of gadolinium in the brain parenchyma of patients with normal renal function following repeat gadolinium-enhanced MRIs. Gadolinium has also been detected in the skin, bones, and livers of patients with normal renal function following repeat MRIs with commercially available GBCA.

The theory of transmetallation has been quoted as a rationale for patients receiving GBCA and developing NSF. Also known as the dechelation or dissociation theory, this theory recognizes the notable differences in the comparative bond strength and kinetics of dissociation of the bonds between the gadolinium ion and ligand molecules used in GBCA. The kinetics of the dissociation 
strength of these bonds among the linear GBCA in general is faster than that for the macrocyclic GBCA, suggesting that dissociation of the gadolinium ion from its ligand molecule would be greater for linear and especially nonionic linear agents than for macrocyclic agents. Precisely such results have been shown in vivo. ${ }^{10-22}$

Only low single-digit numbers of cases of NSF have been seen following unconfounded administration of macrocyclic GBCA. As discussed at the December 8, 2009, FDA Advisory Committee, ${ }^{1}$ there are several hundred confirmed cases of NSF following unconfounded administration of the linear nonionic gadolinium-based contrast agent, gadodiamide, with several dozen following unconfounded administration of the other linear nonionic gadolinium-based contrast agent, gadoversetamide.

However, the ability of this theory alone to explain clinical observations is called into question with roughly 100 cases of NSF following unconfounded administration of the linear ionic agent gadopentetate, yet zero or 1 possibly case following unconfounded administration of the linear ionic agent gadobenate. ${ }^{23,24}$ These differences cannot be ascribed to the relative market share differences alone. $^{25}$

The lack of clarity as to causation is compounded by the concern that perhaps NSF might actually represent one extreme on a spectrum of gadolinium-related issues. In other words, there is a concern that a so-called "subclinical NSF" might exist in which some changes may be histologically present but not clinically manifest at lower total exposure levels to various GBCA.

To that end, Phase I of our study was designed to evaluate the incidence of NSF following administration of gadobenate in patients with chronic renal disease who would be expected to be at the highest risk for NSF. Phase II involved measuring gadolinium levels in the skin of patients with impaired renal function who did not have NSF but had undergone at least 1 contrastenhanced MR imaging study with gadobenate.

This study was performed to attempt to further analyze and quantify any NSF-related risks associated with this linear GBCA.

\section{MATERIALS AND METHODS}

\section{Phase I}

As part of a clinical quality-assurance project initiated in 2007 at the University of Pittsburgh Medical Center, we recorded data for all clinical patients with impaired renal function (defined as estimated glomerular filtration rate [eGFR] values of $<60 \mathrm{~mL} / \mathrm{min} /$ $1.73 \mathrm{~m}^{2}$ ) who underwent clinically requested contrast-enhanced MR imaging examinations following a clinical benefit-risk assessment in which the outcome was to proceed with the examination.

For this project, all patients who were identified as having at least moderate chronic kidney disease who underwent clinically indicated contrast-enhanced MR imaging with gadobenate were identified from our clinical quality-assurance data base noted above from July 2007 through June 2014 (inclusive). Institutional review board approval for this study was granted in addition to the ongoing clinical quality-assurance project approval and oversight noted above. For each patient with impaired renal function, contemporaneous recording was made of the patient's name and identification number, weight, the administered MR imaging contrast agent name and dose, and the most recently available eGFR value. A neutral third party reviewed this list of clinical patients and compared it against the medical record data base of deceased patients in the health care system. After we excluded patients identified as deceased, the contact information for the remaining patients was procured from medical records, and attempts were made by the neutral third party to contact each of these patients for NSF-screening purposes. The order in which the patients were contacted was such that the first patients to be contacted were those with the lowest eGFR level at time of gadobenate administration. Because mortality was expected to be highest among those with the greatest levels of impairment of renal function, we opted to begin with those patients to successfully screen as many as possible in the earliest stages of this study.

Using the screening criteria established by Lima et $\mathrm{al}^{26}$ we verbally screened all contacted patients with an 8-question questionnaire that focused on cutaneous and musculoskeletal manifestations of NSF. Lima et al had demonstrated that affirmative responses to $\geq 3$ of the 8 closed-ended (yes/no) questions yielded a $90 \%$ sensitivity and $70 \%$ specificity for NSF. On the basis of differences in proposed prevalence values, this outcome yielded a positive predictive value for this questionnaire that ranged from a somewhat disappointing $0.3 \%$ to $39.7 \%$, but, at the same time, a negative predictive value, which ranged from $97 \%$ to $>99 \%$. Therefore, a negative response to this questionnaire was thought to reliably exclude a diagnosis of NSF, whereas a positive response to at least 3 of the questions posed in this questionnaire was deemed worthy of further investigation because specificity and positive predictive values were insufficient for conclusive diagnoses based on the questionnaire alone.

During the execution of Phase I of this study, patients who were screened as negative for NSF were asked if they would permit us to contact them at a later date for possible inclusion in a research study. Only those who responded in the affirmative were advanced to Phase II of this study.

\section{Phase II}

After the conclusion of Phase I of this study, all patients who screened negative for NSF and who gave permission for future contact were again contacted and recruited to be possible participants in Phase II of this study. These patients had impaired renal function and had undergone at least $1 \mathrm{MR}$ imaging examination enhanced with intravenously administered gadobenate. Study participation entailed undergoing a purely research-generated punch deep skin biopsy of the lateral thigh. These biopsies were then analyzed using inductively coupled plasma mass spectrometry (ICPMS) for gadolinium-level quantification in Dr Whitney High's laboratory (Department of Dermatology \& Dermatopathology, University of Colorado School of Medicine). The ICP-MS methodology is outlined in a previous publication by High et al, ${ }^{7}$ from 2007, which reported gadolinium levels in the skin of patients with NSF; this methodology has not changed.

\section{RESULTS}

\section{Phase I}

A total of 2914 patients were identified who had eGFR values of $<60 \mathrm{~mL} / \mathrm{min} / 1.73 \mathrm{~m}^{2}$ and who underwent at least 1 contrast- 

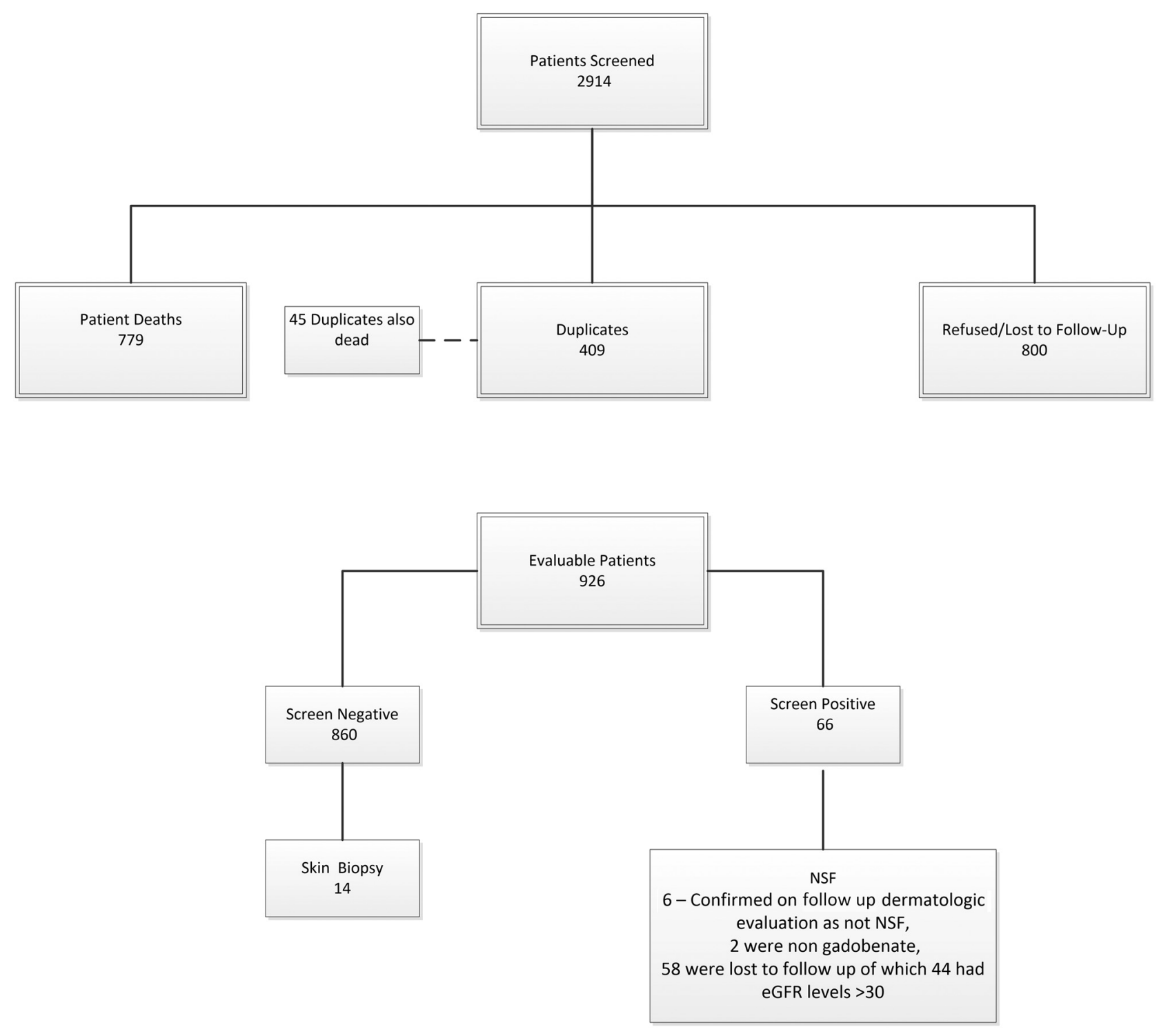

FIG 1. Patient selection.

Table 1: Dose distribution of 926 patients

\begin{tabular}{lc}
\hline & Dose (Full Dose $=0.1 \mathrm{mMol} / \mathbf{k g}$ ) \\
\hline Patients receiving gadobenate & Double \\
1 & 1.5 \\
3 & Full \\
334 & 0.75 \\
15 & 0.5 \\
554 & 0.25 \\
17 & \\
Other GBCA & \\
1 gadoxetate & \\
1 gadobutrol & \\
\hline
\end{tabular}

enhanced MR imaging examination with gadobenate (Fig 1). Of these, 1988 were excluded due to death (779), duplicates (409, deceased patient duplicates numbered 45 of these 409), or patients who refused contact/cooperation or were lost to followup (800). Of the remaining 926 patients (Table 1), all except 66 screened negative for NSF. Of the 66 who had responded yes to $\geq 3$ questions in the NSF screening questionnaire, 6 patients were seen and evaluated by a dermatologist and were confirmed to have another diagnosis and not NSF (no biopsy required), 19 lived too far away/could not return for follow-up at our institution, 10 refused follow-up care, 24 did not return multiple (at least 3) separate calls/messages, 3 had dementia/were in nursing home facilities, 2 had died, and 2 had received nongadobenate gadolinium-based contrast agents (1 gadoxetate, 1 gadobutrol).

Of the 860 patients screened as not having NSF, 17 (2\%) had eGFR levels of $<15 \mathrm{~mL} / \mathrm{min} / 1.73 \mathrm{~m}^{2}, 51$ (6\%) had eGFR levels of $15<30 \mathrm{~mL} / \mathrm{min} / 1.73 \mathrm{~m}^{2}, 234$ (27\%) had eGFR levels of $30<45 \mathrm{~mL} / \mathrm{min} / 1.73 \mathrm{~m}^{2}, 534(62 \%)$ had eGFR levels of $45<60 \mathrm{~mL} / \mathrm{min} / 1.73 \mathrm{~m}^{2}$, and $24(3 \%)$ had no concurrent eGFR data available or had eGFR levels of $>60$ but did have a history of known renal disease. There were no cases of NSF identified either in the screening process using the questionnaire or among those examined directly by the dermatologist and who had responded yes to $\geq 3$ questions on the screening questionnaire. In 4 patients, there were nonspecific findings that did not require biopsy ( 1 of these 4 had undergone an 
unrelated clinical biopsy of her lower leg with nonspecific findings that were not consistent with NSF); in another, there was dyspigmentation of the skin consistent with postinflammatory pigment changes secondary to trauma; and one had induration of the distal lower extremities consistent with lipodermatosclerosis.

Of the 66 patients who had responded positively to $\geq 3$ questions, 2 had received other GBCA (1 gadoxetate, 1 gadobutrol) and 2 patients were found to have had eGFR levels exceeding 59 at time of administration and were thus excluded from further analysis. Of the remaining 62 patients, 6 (10\%) had eGFR levels of $<15 \mathrm{~mL} / \mathrm{min} / 1.73 \mathrm{~m}^{2}, 11$ (18\%) had eGFR levels of $15<30 \mathrm{~mL} /$ $\min / 1.73 \mathrm{~m}^{2}, 19(31 \%)$ had eGFR levels of $30<45 \mathrm{~mL} / \mathrm{min} / 1.73 \mathrm{~m}^{2}$, and 25 (40\%) had eGFR levels of $45<60 \mathrm{~mL} / \mathrm{min} / 1.73 \mathrm{~m}^{2}$. One patient with known renal disease did not have an eGFR before GBCA administration and was excluded from the tally.

Of the 6 patients who had responded positively to $\geq 3$ questions and who were examined by a dermatologist, one (17\%) had eGFR levels of $<15 \mathrm{~mL} / \mathrm{min} / 1.73 \mathrm{~m}^{2}$, none (0\%) had eGFR levels of $15<30 \mathrm{~mL} / \mathrm{min} / 1.73 \mathrm{~m}^{2}$, one (17\%) had eGFR levels of $30<45 \mathrm{~mL} / \mathrm{min} / 1.73 \mathrm{~m}^{2}$, and 4 patients (67\%) had eGFR levels of $45<60 \mathrm{~mL} / \mathrm{min} / 1.73 \mathrm{~m}^{2}$.

\section{Phase II}

A total of 14 patients with renal impairment who screened negative for NSF on the screening questionnaire consented to participate in this phase of the study and successfully underwent an elective research-motivated deep skin punch biopsy and gadolinium-level quantification using ICP-MS (Fig 2). The measured eGFR values for these 14 research subjects ranged from 26 to $59 \mathrm{~mL} / \mathrm{min} / 1.73 \mathrm{~m}^{2}$. The measured gadolinium values in the skin biopsies of these patients ranged from $<0.05$ to $1.1 \mu \mathrm{g} / \mathrm{g}$ (Table 2). These values were all judged to be consistent with background values for this laboratory and were distinctly lower than gadolinium levels typically measured in this lab for skin biopsies of patients with NSF in whom skin-sample gadolinium levels ranged from 4.8 to $106 \mu \mathrm{g} / \mathrm{g}$.

\section{DISCUSSION}

The transmetallation theory has been broadly cited to explain how NSF develops and the mechanism for potential safety issues associated with retained/residual gadolinium following clinical gadolinium administration. However, the transmetallation theory itself does not sufficiently explain the relative incidence of NSF. Certain inconsistencies seem to be present if we seek to explain the NSF incidence on the basis of the transmetallation theory alone. For example, gadopentetate and gadobenate are both linear ionic gadolinium-based contrast agents, yet there is a large difference in the number of cases of NSF associated with their prior unconfounded administration that cannot be explained by relative market share differences. ${ }^{25}$

The lack of clarity as to causation is compounded by the concern that perhaps NSF might actually represent one extreme on a spectrum of gadolinium-related issues. In other words, there is a concern that a so-called subclinical NSF might exist in which

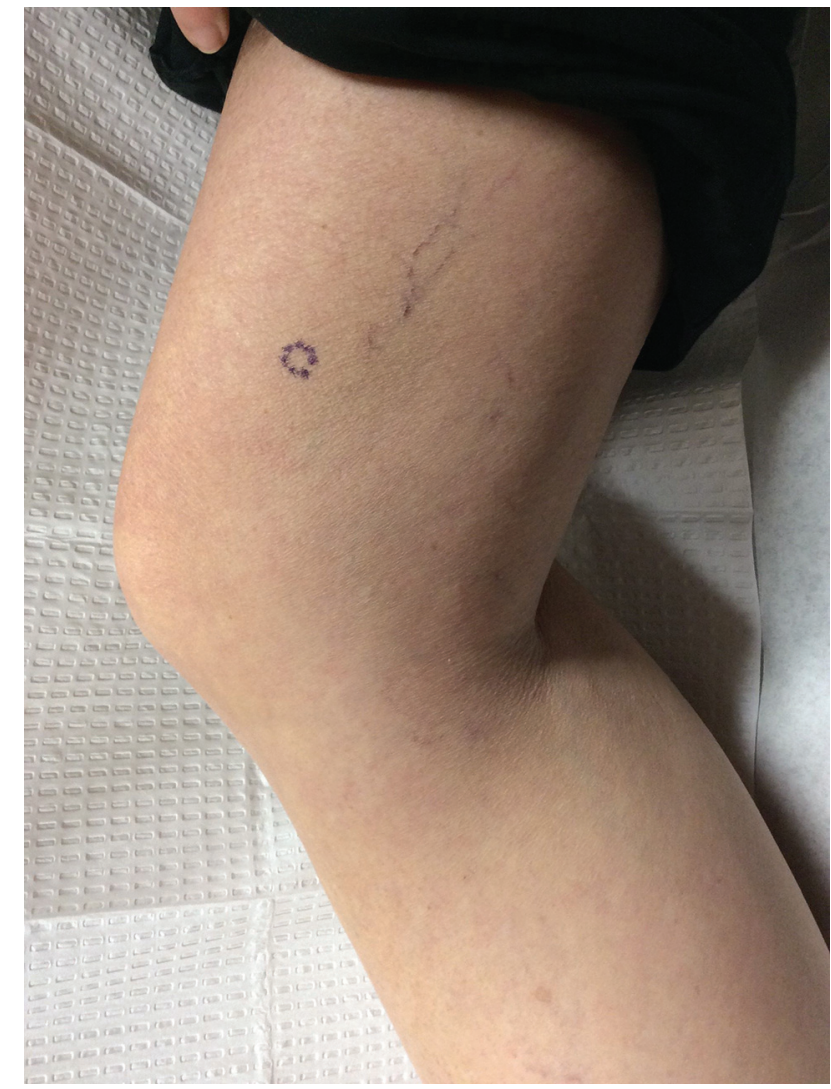

FIG 2. Location marked is representative of the biopsy location on each of the 14 research subjects studied.

Table 2: Subject biopsy details, including gadolinium level and number of prior MRIs

\begin{tabular}{|c|c|c|c|c|}
\hline $\begin{array}{c}\text { Subject } \\
\text { No. }\end{array}$ & $\begin{array}{c}\text { Biopsy } \\
\text { Weight (mg) }\end{array}$ & $\begin{array}{c}\text { Gadolinium } \\
(\mu \mathrm{g} / \mathrm{g})\end{array}$ & eGFR & $\begin{array}{l}\text { No. Prior MR } \\
\text { Imagings }\end{array}$ \\
\hline 1 & 1.158 & $<0.05$ & 39 & 1 \\
\hline 2 & 0.638 & 0.57 & 33 & 3 \\
\hline 3 & 0.802 & 0.15 & 26 & 3 \\
\hline 4 & 0.72 & 0.11 & 49 & 3 \\
\hline 5 & 2.505 & 0.27 & 52 & 8 \\
\hline 6 & 0.748 & $<0.05$ & 33 & 1 \\
\hline 7 & 1.213 & 0.14 & 50 & 2 \\
\hline 8 & 1.064 & 0.08 & 51 & 2 \\
\hline 9 & 0.46 & 0.06 & 37 & 9 \\
\hline 10 & 1.07 & 0.33 & 40 & 2 \\
\hline 11 & 0.74 & 0.10 & 59 & 2 \\
\hline 12 & 0.70 & 0.08 & 46 & 2 \\
\hline 13 & 0.52 & 0.28 & 53 & 3 \\
\hline 14 & 0.29 & 1.1 & 53 & 1 \\
\hline
\end{tabular}

some changes may be histologically present but not clinically manifest at lower total exposure levels to various GBCA.

This study was undertaken in an effort to further analyze and quantify the NSF risk associated with gadobenate administration, specifically to the population deemed to be at highest risk for this disease, namely, those with significant renal disease. The findings of this study, revealing no cases of NSF associated with the administration of gadobenate to patients with significant, serious, or end-stage renal disease support those of other publications describing the observed NSF incidence in this specific patient population. $^{27-30}$ 
Table 3: Gadolinium deposition in skin samples from patients with NSF (adapted from Roberts et $\mathrm{al}^{34}$ )

\begin{tabular}{|c|c|c|c|c|c|}
\hline \multirow[b]{2}{*}{ Lead Author } & \multirow[b]{2}{*}{$\begin{array}{l}\text { No. of } \\
\text { Patients } \\
\text { with NSF }\end{array}$} & \multirow[b]{2}{*}{$\begin{array}{l}\text { Range of Gadolinium } \\
\text { Levels }(\mu \mathrm{g} / \mathrm{g})\end{array}$} & \multirow[b]{2}{*}{ No. of Controls } & \multirow[b]{2}{*}{$\begin{array}{c}\text { Range of } \\
\text { Gadolinium Levels } \\
(\mu \mathrm{g} / \mathrm{g})\end{array}$} & \multirow{2}{*}{$\begin{array}{c}\text { Comment } \\
\text { Inductively Coupled Mass } \\
\text { Spectrometry (ICP-MS) } \\
\text { Techniques }\end{array}$} \\
\hline & & & & & \\
\hline High et al ${ }^{7}$ & 5 & $4.8-106$ & 1 & 0 & $\begin{array}{l}\text { Limits of detection not } \\
\text { provided }\end{array}$ \\
\hline \multirow[t]{5}{*}{ Khurana et $\mathrm{al}^{35}$} & 6 & $57.2-717.8$ & 2 & & \\
\hline & & & Infant Foreskin & $\begin{array}{l}0.0 \text { (reported as } \\
\text { ppm) }\end{array}$ & \\
\hline & & & 2 Multiple Sclerosis & 0.1 & 3-5 Gadolinium MRIs \\
\hline & & & Patients & & $\begin{array}{l}1 \mathrm{MS} \text { patient marginal } \\
\text { renal function }\end{array}$ \\
\hline & & & Scleroderma Patient & 0.2 & \\
\hline \multirow[t]{2}{*}{ Christensen et $\mathrm{al}^{36}$} & 13 & Affected skin 6.3-348.7 & 13 & $2-0.1$ & $\begin{array}{l}2 \text { with previous GBCA } \\
\text { administration }\end{array}$ \\
\hline & & Unaffected skin 0.6-68.2 & & $\begin{array}{l}11 \text { below detectable } \\
\text { range }\end{array}$ & \\
\hline Roberts et $\mathrm{al}^{34}$ & $1 ?$ & 14.5 & & & $\begin{array}{l}61 \mathrm{GBCA} \text { MRIs, eGFR }>59 \\
\mathrm{~mL} / \mathrm{min} / 1.73 \mathrm{~m}^{2}\end{array}$ \\
\hline
\end{tabular}

Note:-? indicates NSF diagnosis was not confirmed.

With gadolinium having been reported in the skin of patients with NSF (Table 3), ${ }^{5,31}$ it is interesting to note the lack of elevation of gadolinium levels in the 14 subjects with significant renal disease who had previously undergone at least 1 contrastenhanced MR imaging examination with gadobenate.

It remains unclear whether the presence of gadolinium in NSF skin lesions is etiologically related, secondary, or incidental in nature, and this lack of clarity provides further evidence of differences between patients with NSF with renal disease relative to those with significant renal disease who had undergone gadobenate-enhanced MR imaging but did not have clinical NSF.

\section{Limitations}

The study is limited in that there are several patients who had responded "yes" to $\geq 3$ screening questions about whom there is no follow-up information available due to patient refusals, death, lack of access to follow-up, and so forth. However, the data remain quite reassuring insofar as most patients in this study with significant renal disease who had undergone a gadobenate-enhanced MR imaging examination were able to be successfully screened, and no cases of NSF were found. Another limitation of the examination is that the vast majority of those with significant renal disease in this study who did receive gadobenate received a half-dose and not a full dose. However, this specific gadolinium-based contrast agent has a high relaxivity, and several publications have already documented the favorable diagnostic sensitivities of partial-dose gadobenate relative to studies performed following full doses of several of the other lower relaxivity GBCA used for neuroradiologic imaging. ${ }^{32,33}$ Thus, from a clinical point of view, partial-dose administration of this agent may well be an appropriate diagnostic comparator against a full dose of lower relaxivity agents, with the added benefit of having administered to the patient proportionally fewer gadolinium ions by so doing.

The gadolinium levels were obtained after the patient volunteered for the study and therefore at various times following the last gadolinium contrast MR imaging, the date of which was not available to the study team. We, therefore, view these levels as a "snapshot" at an indeterminate time from the last administration.

Gadolinium levels should be considered either negligible or large; exact quantitation, given the small mass of the skin biopsy, may not be achievable. The small mass of the skin biopsies introduces the possibility of contamination during multiple processing procedures to determine gadolinium levels such as the following:

- Metal in the punch biopsy device

- Metal in the forceps

- Non-reagent grade chemicals used in the processing procedures

- Contamination from the microtomes

- Contamination from the water baths.

Consistent with other similar reports, in our study of 860 patients with varying levels of impaired renal function (defined as $<60 \mathrm{~mL}$./min $/ 1.73 \mathrm{~m}^{2}$ ) who underwent clinically indicated MR imaging examinations with gadobenate, subsequent screening failed to reveal any cases of nephrogenic systemic fibrosis. In comparison with previous publications, we screened patients with a uniform, previously validated questionnaire and performed skin biopsies. Previous studies also faced the methodologic difficulty of accounting for drop-out and deceased patients. Gadolinium-level quantification by ICP-MS of deep skin punch biopsies of 14 research subjects with impaired renal function who did not have clinical signs or symptoms of NSF and who had previously undergone at least 1 contrast-enhanced MR imaging examination with gadobenate failed to reveal any measurable elevation of skin gadolinium levels beyond that found in healthy controls.

\section{CONCLUSIONS}

No evidence of NSF was found in 860 patients with moderate or worse chronic kidney disease for whom follow-up was available 
and who had received (predominantly half dose) gadobenate for clinical MR imaging examinations. Additionally, in 14 patients with impaired renal function who underwent at least 1 gadobenate-enhanced MR imaging examination and who did not have clinical NSF, ICP-MS determined that gadolinium levels in the skin were exceedingly low and were considered essentially at background levels without evidence of abnormal gadolinium accumulation. Implications for patient care are that NSF was not identified in patients with renal disease undergoing predominantly half-dose gadobenate contrast MR imaging and that gadolinium skin retention is minimal in these patients.

\section{ACKNOWLEDGMENT}

The authors wish to thank Dr Whitney High for his assistance in testing skin samplings for gadolinium.

Disclosures: Emanuel Kanal—UNRELATED: Consultancy: Bracco Diagnostics, GE Healthcare, Guerbet, Comments: MR imaging safety consulting.

\section{REFERENCES}

1. Balzer T. Presence of Gadolinium (Gd) in the Brain and Body: Presentation to the Medical Imaging Drugs Advisory Committee, September 8, 2017. FDA. Silver Spring, Md: U.S. Food and Drug Administration. https://www.fda.gov/media/107670/download. Accessed February 5, 2020

2. McDonald RJ, Levine D, Weinreb J, et al. Gadolinium retention: a research roadmap from the 2018 NIH/ACR/RSNA Workshop on Gadolinium Chelates. Radiology 2018;289:517-34 CrossRef Medline

3. Boyd AS, Zic JA, Abraham JL. Gadolinium deposition in nephrogenic fibrosing dermopathy. J Am Acad Dermatol 2007;56:27-30 CrossRef Medline

4. Grobner T. Gadolinium: a specific trigger for the development of nephrogenic fibrosing dermopathy and nephrogenic systemic fibrosis? Nephrol Dial Transplant 2006;21:1104-08 CrossRef Medline

5. Birka M, Wentker KS, Lusmoller E, et al. Diagnosis of nephrogenic systemic fibrosis by means of elemental bioimaging and speciation analysis. Anal Chem 2015;87:3321-28 CrossRef Medline

6. High WA, Ayers RA, Chandler J, et al. Gadolinium is detectable within the tissue of patients with nephrogenic systemic fibrosis. $J$ Am Acad Dermatol 2007;56:21-26 CrossRef Medline

7. High WA, Ayers RA, Cowper SE. Gadolinium is quantifiable within the tissue of patients with nephrogenic systemic fibrosis. $\mathrm{J} \mathrm{Am}$ Acad Dermatol 2007;56:710-12 CrossRef Medline

8. Grobner T, Prischl FC. Gadolinium and nephrogenic systemic fibrosis. Kidney Int 2007;72:260-64 CrossRef Medline

9. Kanda T, Ishii K, Kawaguchi H, et al. High signal intensity in the dentate nucleus and globus pallidus on unenhanced T1-weighted MR images: relationship with increasing cumulative dose of a gadolinium-based contrast material. Radiology 2014;270:834-41 CrossRef Medline

10. Kanda $\mathrm{T}$, Osawa $\mathrm{M}$, Oba $\mathrm{H}$, et al. High signal intensity in dentate nucleus on unenhanced T1-weighted MR images: association with linear versus macrocyclic gadolinium chelate administration. Radiology 2015;275:803-09 CrossRef Medline

11. Boyken J, Frenzel T, Lohrke J, et al. Gadolinium accumulation in the deep cerebellar nuclei and globus pallidus after exposure to linear but not macrocyclic gadolinium-based contrast agents in a retrospective pig study with high similarity to clinical conditions. Invest Radiol 2018;53:278-85 CrossRef Medline

12. Jost G, Lenhard DC, Sieber MA, et al. Signal increase on unenhanced T1-weighted images in the rat brain after repeated, extended doses of gadolinium-based contrast agents: comparison of linear and macrocyclic agents. Invest Radiol 2016;51:83-89 CrossRef Medline
13. Lohrke J, Frisk AL, Frenzel T, et al. Histology and gadolinium distribution in the rodent brain after the administration of cumulative high doses of linear and macrocyclic gadolinium-based contrast agents. Invest Radiol 2017;52:324-33 CrossRef Medline

14. Kartamihardja AA, Nakajima T, Kameo S, et al. Distribution and clearance of retained gadolinium in the brain: differences between linear and macrocyclic gadolinium-based contrast agents in a mouse model. Br J Radiol 2016;89:20160509 CrossRef Medline

15. McDonald RJ, McDonald JS, Dai D, et al. Comparison of gadolinium concentrations within multiple rat organs after intravenous administration of linear versus macrocyclic gadolinium chelates. Radiology 2017;285:536-45 CrossRef Medline

16. Moser FG, Watterson CT, Weiss $S$, et al. High signal intensity in the dentate nucleus and globus pallidus on unenhanced T1-weighted MR images: comparison between gadobutrol and linear gadolinium-based contrast agents. AJNR Am J Neuroradiol 2018;39:421-26 CrossRef Medline

17. Radbruch A, Weberling LD, Kieslich PJ, et al. Intraindividual analysis of signal intensity changes in the dentate nucleus after consecutive serial applications of linear and macrocyclic gadolinium-based contrast agents. Invest Radiol 2016;51:683-90 CrossRef Medline

18. Rasschaert M, Emerit A, Fretellier N, et al. Gadolinium retention, brain $\mathrm{T} 1$ hyperintensity, and endogenous metals: a comparative study of macrocyclic versus linear gadolinium chelates in renally sensitized rats. Invest Radiol 2018;53:328-37 CrossRef Medline

19. Robert P, Lehericy S, Grand S, et al. T1-weighted hypersignal in the deep cerebellar nuclei after repeated administrations of gadolinium-based contrast agents in healthy rats: difference between linear and macrocyclic agents. Invest Radiol 2015;50:473-80 CrossRef Medline

20. Runge VM. Macrocyclic versus linear gadolinium chelates. Invest Radiol 2015;50:811 CrossRef Medline

21. Runge VM. Commentary on T1-weighted hypersignal in the deep cerebellar nuclei after repeated administrations of gadoliniumbased contrast agents in healthy rats: difference between linear and macrocyclic agents. Invest Radiol 2015;50:481-82 CrossRef Medline

22. Schmitt-Willich $\mathrm{H}$. Stability of linear and macrocyclic gadoliniumbased contrast agents. Br J Radiol 2007;80:581-82 CrossRef Medline

23. Edwards BJ, Laumann AE, Nardone B, et al. Advancing pharmacovigilance through academic-legal collaboration: the case of gadolinium-based contrast agents and nephrogenic systemic fibrosis: a Research on Adverse Drug Events and Reports (RADAR) report. Br J Radiol 2014;87:20140307 CrossRef Medline

24. Lohani S, Golenbiewski J, Swami A, et al. A unique case of nephrogenic systemic fibrosis from gadolinium exposure in a patient with normal eGFR. BMJ Case Rep 2017;2017 CrossRef Medline

25. FDA. Meeting Materials Cardiovascular and Renal Drugs Advisory Committee. March 19, 2009. Adelphi, Maryland. https://www. federalregister.gov/documents/2009/02/13/E9-3089/cardiovascularand-renal-drugs-advisory-committee-notice-of-meeting. Accessed February 5, 2020

26. Lima XT, Alora-Palli MB, Kimball AB, et al. Validation of a screening instrument for nephrogenic systemic fibrosis. Arthritis Care Res (Hoboken) 2013;65:637-42 CrossRef Medline

27. Bryant BJ, Im K, Broome DR. Evaluation of the incidence of nephrogenic systemic fibrosis in patients with moderate renal insufficiency administered gadobenate dimeglumine for MRI. Clin Radiol 2009;64:706-13 CrossRef Medline

28. Nandwana SB, Moreno CC, Osipow MT, et al. Gadobenate dimeglumine administration and nephrogenic systemic fibrosis: is there a real risk in patients with impaired renal function? Radiology 2015;276:741-47 CrossRef Medline

29. Soulez G, Bloomgarden DC, Rofsky NM, et al. Prospective cohort study of nephrogenic systemic fibrosis in patients with stage 3-5 chronic kidney disease undergoing MRI with injected gadobenate dimeglumine or gadoteridol. AJR Am J Roentgenol 2015;205:469-78 CrossRef Medline 
30. Bruce R, Wentland AL, Haemel AK, et al. Incidence of nephrogenic systemic fibrosis using gadobenate dimeglumine in 1423 patients with renal insufficiency compared with gadodiamide. Invest Radiol 2016;51:701-05 CrossRef Medline

31. Roberts DR, Chatterjee AR. The critical need for pediatric and juvenile animal research addressing gadolinium retention in the developing body. Invest Radiol 2019;54:72-75 CrossRef Medline

32. Vaneckova M, Herman M, Smith MP, et al. The benefits of high relaxivity for brain tumor imaging: results of a multicenter intraindividual crossover comparison of gadobenate dimeglumine with gadoterate meglumine (the BENEFIT Study). AJNR Am J Neuroradiol 2015;36:1589-98 CrossRef Medline

33. Khouri Chalouhi K, Papini GD, Bandirali M, et al. Less is better? Intraindividual and interindividual comparison between $\mathbf{0 . 0 7 5}$ $\mathrm{mmol} / \mathrm{kg}$ of gadobenate dimeglumine and $0.1 \mathrm{mmol} / \mathrm{kg}$ of gadoterate meglumine for cranial MRI. Eur J Radiol 2014;83:1245-49 CrossRef Medline

34. Roberts DR, Lindhorst SM, Welsh CT, et al. High levels of gadolinium deposition in the skin of a patient with normal renal function. Invest Radiol 2016;51:280-89 CrossRef Medline

35. Khurana A, Greene JF Jr, High WA. Quantification of gadolinium in nephrogenic systemic fibrosis: re-examination of a reported cohort with analysis of clinical factors. $J$ Am Acad Dermatol 2008;59:218-24 CrossRef Medline

36. Christensen KN, Lee CU, Hanley MM, et al. Quantification of gadolinium in fresh skin and serum samples from patients with nephrogenic systemic fibrosis. J Am Acad Dermatol 2011;64:91-96 CrossRef Medline 